\title{
Nylon/Graphene Oxide Electrospun Composite Coating
}

\author{
Carmina Menchaca-Campos, ${ }^{1}$ César García-Pérez, ${ }^{1}$ Iván Castañeda, ${ }^{1}$ \\ Miguel A. García-Sánchez, ${ }^{2}$ René Guardián, ${ }^{1}$ and Jorge Uruchurtu' ${ }^{1}$ \\ ${ }^{1}$ UAEM Centro de Investigación en Ingeniería y Ciencias Aplicadas, Avenida Universidad 1001, \\ Col Chamilpa, 62209 Cuernavaca, MOR, Mexico \\ ${ }^{2}$ Departamento de Química, UAM-Iztapalapa, Avenida San Rafael Atlixco 186, Vicentina, 09340 México, DF, Mexico
}

Correspondence should be addressed to Jorge Uruchurtu; juch25@uaem.mx

Received 23 March 2013; Revised 2 July 2013; Accepted 3 July 2013

Academic Editor: Osman Gencel

Copyright (C) 2013 Carmina Menchaca-Campos et al. This is an open access article distributed under the Creative Commons Attribution License, which permits unrestricted use, distribution, and reproduction in any medium, provided the original work is properly cited.

Graphite oxide is obtained by treating graphite with strong oxidizers. The bulk material disperses in basic solutions yielding graphene oxide. Starting from exfoliated graphite, different treatments were tested to obtain the best graphite oxide conditions, including calcination for two hours at $700^{\circ} \mathrm{C}$ and ultrasonic agitation in acidic, basic, or peroxide solutions. Bulk particles floating in the solution were filtered, rinsed, and dried. The graphene oxide obtained was characterized under SEM and FTIR techniques. On the other hand, nylon 6-6 has excellent mechanical resistance due to the mutual attraction of its long chains. To take advantage of the properties of both materials, they were combined as a hybrid material. Electrochemical cells were prepared using porous silica as supporting electrode of the electrospun nylon/graphene oxide films for electrochemical testing. Polarization curves were performed to determine the oxidation/reduction potentials under different acidic, alkaline, and peroxide solutions. The oxidation condition was obtained in $\mathrm{KOH}$ and the reduction in $\mathrm{H}_{2} \mathrm{SO}_{4}$ solutions. Potentiostatic oxidation and reduction curves were applied to further oxidize carbon species and then reduced them, forming the nylon 6-6/functionalized graphene oxide composite coating. Electrochemical impedance measurements were performed to evaluate the coating electrochemical resistance and compared to the silica or nylon samples.

\section{Introduction}

Graphite oxide is a compound of carbon, oxygen, and hydrogen in variable ratios, commonly obtained by treating graphite with strong oxidizers. Strictly speaking "oxide" is an incorrect but historically established name, since graphite is not a metal. The bulk material disperses in basic solutions yielding monomolecular sheets, known as graphene oxide by analogy to graphene, the single-layer form of graphite [1]. Graphene oxide (GO) sheets have recently attracted substantial interest as a possible intermediate for the manufacture of graphene. It typically preserves the layer structure of the parent graphite, but the layers are buckled and the interlayer spacing is about two times larger $(\sim 0.7 \mathrm{~nm})$ than that of graphite. Graphene oxide layers are about $1.1 \pm 0.2 \mathrm{~nm}$ thick [2-6]. The edges of each layer are terminated with carboxyl and carbonyl groups. The detailed structure is still not understood due to the strong disorder and irregular packing of the layers [1].

One of the methods used to separate the layers of graphite consists in an aggressive oxidative processes which functionalize the periphery and some places of the graphene surface, principally in those places in which defects exist. As consequence oxygenated organic functions can be attached in those places inducing attractions with polar species and solvents and repulsion with the hydrophobic regions of the grapheme layer. The existence of organic functions attached in the surface and periphery of the grapheme layers made possible its covalent union with other chemical or biochemical species, susceptible of being used in diverse technological areas. This modification induces that layers losses their planarity and promote their separation. 
Since nylon discovery, a great interest has been developed due to its technological importance, its commercial characteristic, and its complexity related to the morphological changes associated to its crystallinity, not only in solid state but also in solution and under melting point conditions. In general, nylon 6-6 (Ny) has excellent mechanical resistance due to the mutual attraction of their long chains due to hydrogen bonds and their cross-linking [7].

Electrospinning is a recognized technique to create polymer fibers with diameter ranging from 40 to 2000 nanometers. Fibers can be electrospun direct from solution or from the fused material state, controlling the diameter size through adjustment of the surface tension, solution concentration, conductivity, and so forth [5-7]. Electrospinning occurs when the electric force of the solution surface overcomes the surface tension and triggers an electric spark provoking the solution to be expelled from the containing device (syringe), and the jet flow impacts, deposits, and is collected in a metal screen. When the expelled material dries out or solidifies, it forms an electric charged fiber, and this could be directed or speeded up by electric forces. In other words, a polymer solution in a syringe is charged to a high electrical potential. As the jet stretches and dries, radial electrical forces cause it to splash repeatedly. The dried, solidified fibers are collected on an electrically conducting screen (Figure 1).

This work proposes a possible application for commercial nylon 6-6 electrospun fibers and functionalized graphene oxide (Ny/FGO) producing a corrosion protection composite coating, through electrochemical procedures. It was characterized throughout spectroscopic analysis and the coating electrochemical performance was evaluated.

\section{Experimental}

2.1. Coating Preparation. Two types of coatings were prepared, from electrospinning commercial nylon 6-6 over porous silica, at ambient temperature. The system consists of a controlled power source (Glassman High Voltage, Inc.) providing a high voltage to create a high electrostatic field, an injector or perfusion pump (SryngePump.com, Model NE300, 11 VDC Volts/Hertz, 0.75 Amperes) generating pressure to a connected syringe, expelling the fluid. When the effects of polarization and electric charge, as a consequence of the electric field are present, a jet solution is triggered over the porous silica collector placed over a conducting screen or plate electrically down earthed (in this case commercial aluminum sheet). During the jet formation, the solvent gradually evaporates and the fluid discharges are induced through the separation distance of the electrodes (syringe tip and collector) breaking up the surface tension across the electric field forming a tangential $\left(\tau_{\mathbf{t}}\right)$ and a normal $\left(\tau_{\mathbf{n}}\right)$ components, forming Taylor's cone (see Figure 1).

2.1.1. Graphene Oxide. Starting from mechanically exfoliated graphite (MEG), different treatments were tested in order to obtain the best graphene oxide (GO) conditions. These included calcinations in a muffle for two hours at $700^{\circ} \mathrm{C}$, in order to remove contaminants and undesirable functional groups that maintain the graphite oxide layers bonded. After

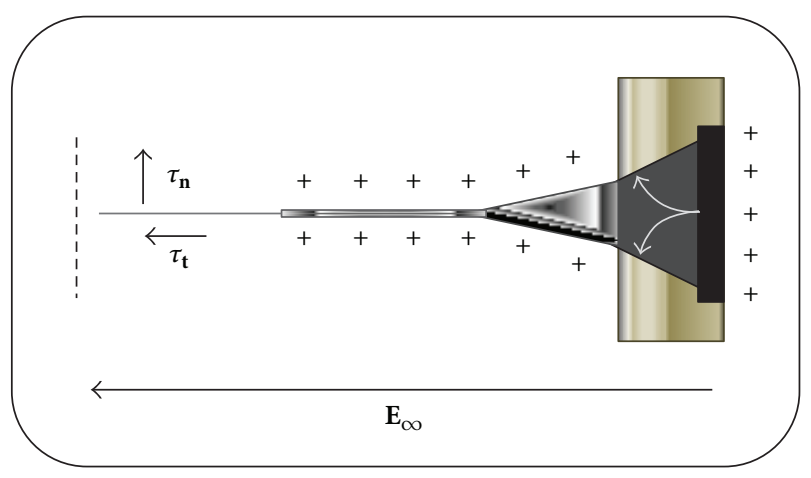

FIGURE 1: Taylor's cone in the electrospinning system.

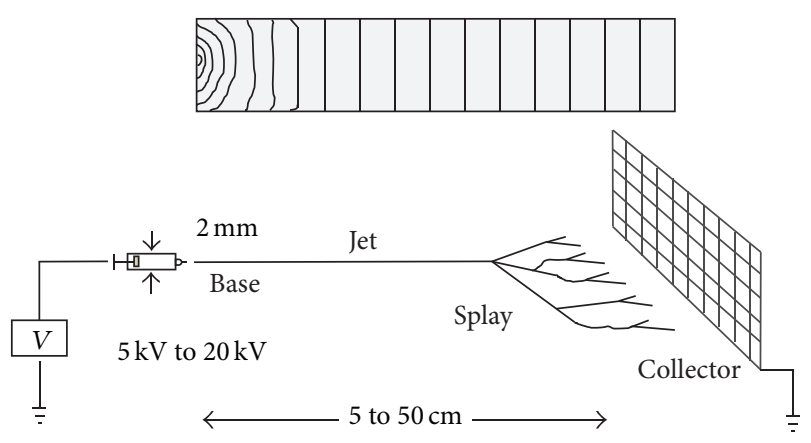

Figure 2: Electrospinning system.

that, ultrasonic agitation for three hours: in formic acid, $\mathrm{KOH}-\mathrm{NaOH}$ basic or peroxide solution was performed. Afterwards, floating particles were collected, filtered, rinsed, and dried at ambient temperature to obtain the GO.

2.1.2. Nylon 6-6 Electrospun Film. Two types of coating samples were prepared; one was electrospinning Nylon (Ny) fibers under environmental room temperature $\left(25^{\circ} \mathrm{C}\right)$ with 1.20 g nylon 6-6 dissolved in $7 \mathrm{ml}$ of formic acid. This mixture was left under gentle agitation for approximately $12 \mathrm{~h}$. The other coating was prepared adding graphene oxide (GO) to the nylon solution. Electrospinning was carried out using a power source and a dosage syringe, at $12 \mathrm{kV}$ voltage and a tip-collector distance of $12 \mathrm{~cm}$ and a flow rate of $0.2 \mathrm{~mL} / \mathrm{h}$ (Figure 2). An electrospun nylon 6-6 film was formed after a few hours and collected over a porous silica (because it is a conductive material) plate used as screen.

\subsection{Electrodes Preparation}

2.2.1. Ny/FGO Electrochemical Coating Preparation. Two different electrospun $\mathrm{Ny} / \mathrm{GO}$ coatings were prepared from a polymeric solution, consisting of $90 \%$ of formic acid, $0.36 \%$ or $2 \%$ by wt. of $\mathrm{GO}$, and the rest of $\mathrm{Ny}$. To functionalize the GO to form the composite coating the system was electrochemically treated, preparing electrochemical cells using porous silica covered with electrospun Ny/GO films as electrodes. Further oxidation and reduction by electrochemical procedures to obtain $\mathrm{Ny} / \mathrm{FGO}$ composite were carried 
out. Polarization curves were performed to determine the best oxidation/reduction potentials under different acidic $\left(\mathrm{H}_{2} \mathrm{SO}_{4}\right)$, alkaline $(\mathrm{KOH})$, and peroxide $\left(\mathrm{H}_{2} \mathrm{O}_{2}\right)$ solutions.

After obtaining the best electrochemical conditions, the procedure adopted was to oxidize in alkaline and reduce in acid solutions, adding up a few drops of hydrazine to suppress the oxygen reduction reaction improving the efficiency of the reduction process to obtain the nylon-graphene oxide composite bonding taking place during this process.

2.2.2. Ny/GO Coating Prepared by Deposit. Another sample of coating was prepared in order to compare the efficiency of the electrospun coating. In this case, a nylon 6-6 electrospun film was collected over a porous silica substrate, and then a GO layer was placed over it, followed by the oxidation/ reduction process from the electrolytic solution, obtaining the Ny/FGO composite coating at the end.

2.3. Characterization. Functionalized graphene oxide samples were characterized using SEM and FTIR techniques. Nylon fiber samples were characterized, and the results were presented by the authors previously [8].

2.3.1. Scanning Electron Microscopy. To determine their size or form, GO flakes samples, used as part of the composite electrode coating for electrochemical measurements, were prepared for SEM (Model LEO operating at $6 \mathrm{kV}$, at 1, 2, and $10 \mathrm{kX}$ resolution) analysis. Flakes were vacuum sputtered and covered with $\mathrm{Au}-\mathrm{Pd}$ to provide conductivity.

Energy dispersive X-Ray spectroscopy (EDX), a semianalytical technique attached to SEM, was performed to determine the elemental analysis of GO in order to corroborate the presence of oxygenated functional groups.

2.3.2. Infrared Spectroscopy (FT-IR). FT-IR spectra were registered, in the frequency range $500-4000 \mathrm{~cm}^{-1}$, resolution $4 \mathrm{~cm}^{-1}$, in a spectrophotometer Model Bruker Vector 22, equipped with ATR accessory and the OPUS 5.5 software.

2.3.3. UV-Visible. UV-visible absorption spectra were recorded on a Cary 5000 UV-Vis-NIR scanning spectrophotometer and using nylon fiber as the reference sample (blank).

2.4. Electrochemical Measurements. Electrochemical measurements, namely, polarization curves and electrochemical impedance (EIS), were performed using a Gill ACM electrochemical instrument. Polarization curves were performed to determine the best oxidation/reduction potentials under different acidic, alkaline, and peroxide solutions. Polarization curves were performed from -1500 to $1500 \mathrm{mV}$ at a rate of $100 \mathrm{mV} / \mathrm{min}$. Potentiostatic oxidation and reduction curves were performed at 1000 and $-1000 \mathrm{mV}$, respectively, versus a $\mathrm{Ag} / \mathrm{AgCl}_{2}$ electrode, to further oxidize carbon species and then to reduce them in both types of $\mathrm{Ny} / \mathrm{GO}$ films. The Ny/FGO composite coatings were formed.

Electrochemical impedance measurements were performed to evaluate the coating and compared to the silica or nylon "only" samples. EIS measurements were done at the open circuit potential, in the frequency interval 10000 to $0.05 \mathrm{~Hz}$ with $\pm 20 \mathrm{mV}$ amplitude using an SCE and a graphite auxiliary electrode. Fifty points were obtained, and 7 decades of frequency were covered during measurements [9-11].

\section{Results}

3.1. SEM Graphene Oxide Characterization. Figure 3 presents the SEM micrographs characterizing the MEG and treated graphite with temperature and different solutions in ultrasound (Figures 3(a) to 3(d)). Apparently the acid or basic treatments render solids consisting of aggregates of smaller, disordered, and slightly folded layers of graphene oxide. In the thermally treated sample a porous structure was observed, probably due to impurities present in the original graphite and eliminated during the thermal treatment at $700^{\circ} \mathrm{C}$ (Figure 3(a)). After the thermal treatment, to facilitate the separation of the graphite plates from the porous structure, a subsequent chemical treatment in acid, basic, and peroxide solutions (formic acid, $\mathrm{KOH}: \mathrm{NaOH}$ or $\mathrm{H}_{2} \mathrm{O}_{2}$ ), and with ultrasonic vibrations was performed (Figures 3(b), 3(c), and $3(\mathrm{~d})$, resp.). This procedure renders a solid with lower dimensions in the graphene oxide plates or sheets, especially in the case for the peroxide solution treatment, in which planar or slightly folded separated GO layers are clearly seen over the surface.

3.2. EDX Graphene Oxide Characterization. Folded particle samples thermally pretreated at $700^{\circ} \mathrm{C}$ followed by ultrasonic vibration in an $\mathrm{H}_{2} \mathrm{O}_{2}$ solution are presented in Figures 4 and 5. A SEM general view (2000x) of the surface and a higher magnification $(10000 \mathrm{x})$ show the effect of this treatment that rendered folded sheets thinner and varied in size.

A folded particle sample was characterized using SEM and EDX as can be seen in Figure 5. The chemical composition of a GO thin sheet (Figure 5(a)) was determined through energy dispersive X-rays (EDX), as seen in Figure 5(b). Sheet characterization shows the presence of carbon and oxygen in its structure, confirming the presence of oxygen groups attached over a structure principally constituted by carbon (Figure 5(b)). The low oxygen percentage may be due to the weak peroxide oxidation process, compared to other chemical oxidation, such as the Hummer's process. The $\mathrm{O} / \mathrm{C}$ ratio obtained in our procedure is 0.048 between the ratios for pristine graphite $(0.014)$ and GO $(0.582)[12,13]$.

3.3. FT-IR Characterization. Taking into consideration the best conditions for the graphene oxide particles formed under peroxide solution, analysis with SEM, FT-IR, and UV was performed. This analysis was carried out to observe the material structural changes and compared to the MEG blank (Figure 6). The graph presents the spectrum obtained for MEG after chemical treatment in the peroxide solution showing characteristic bands related to the graphene oxide (GO), around $1628 \mathrm{~cm}^{-1}$ corresponding to the stretching vibration of the $\mathrm{C}=\mathrm{C}$ bond, assigned to the $\pi$-bonds that form the extended conjugated and aromatic layer of graphene.

Other bands around $1050 \mathrm{~cm}^{-1}$ correspond to the characteristic vibration of $\mathrm{C}-\mathrm{O}$ bonds, as well as the bands 


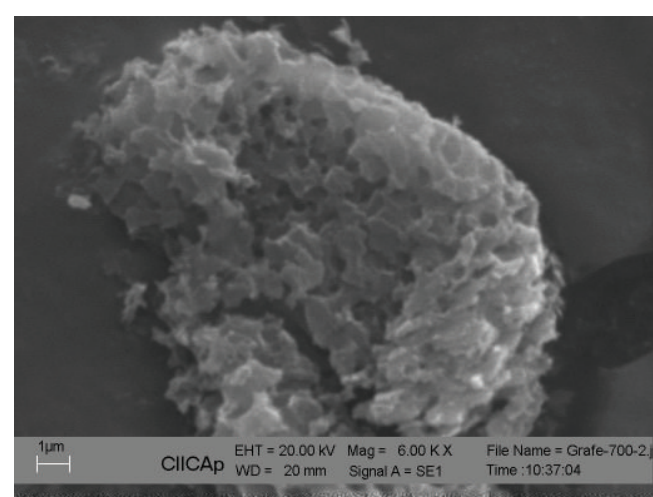

(a)

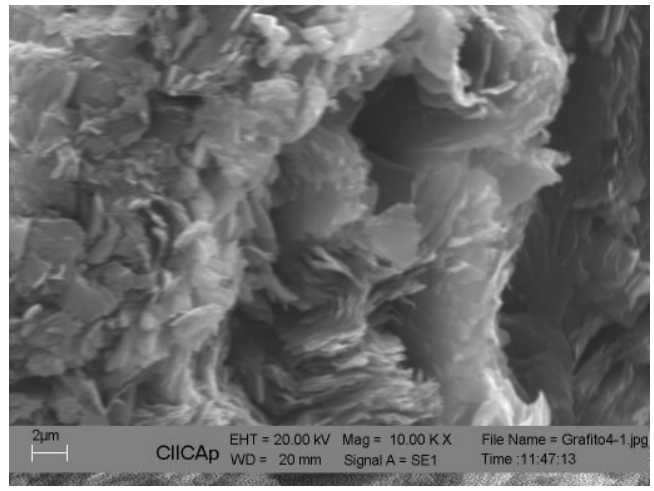

(c)

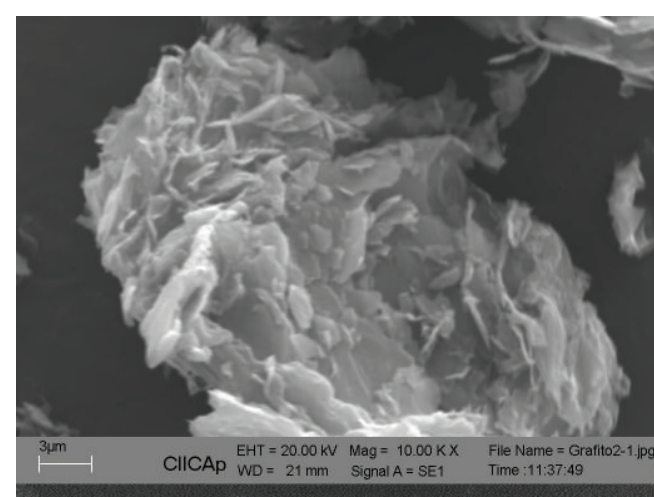

(b)

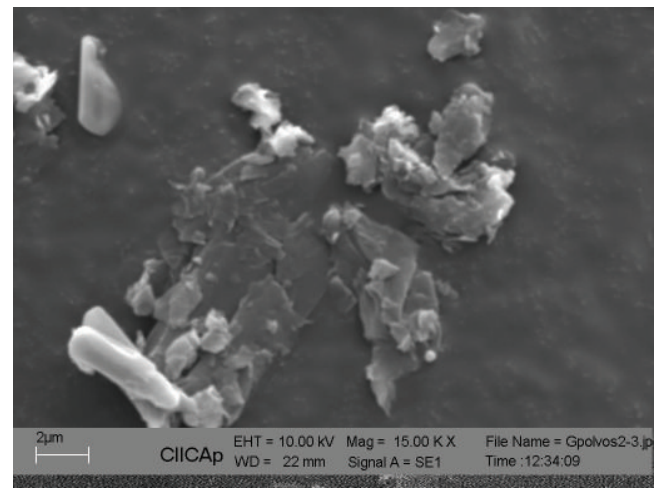

(d)

FIGURE 3: SEM images of MEG under thermal treatment at $700^{\circ} \mathrm{C}$ with temperature and in different solutions with ultrasound: (a) treated to $700^{\circ} \mathrm{C}$, (b) treated to $700^{\circ} \mathrm{C}$ and formic acid, (c) treated to $700^{\circ} \mathrm{C}$ and $\mathrm{KOH}: \mathrm{NaOH} 1 \mathrm{M}(1: 1)$, and (d) treated to $700^{\circ} \mathrm{C}_{\text {and }} \mathrm{H}_{2} \mathrm{O}_{2}$.

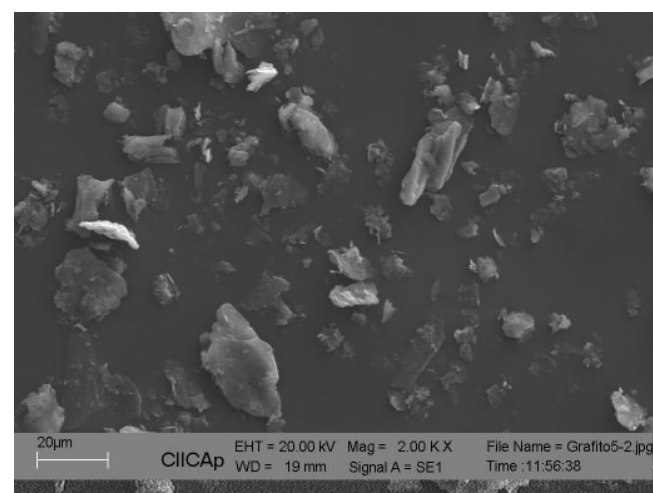

(a) general view

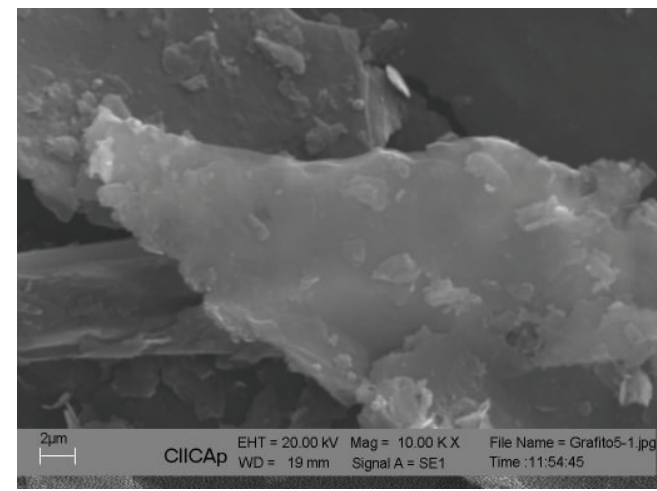

(b) higher magnification

FIgURE 4: SEM images at of the GO sample pretreated at $700^{\circ} \mathrm{C}$ and ultrasonic vibration in $\mathrm{H}_{2} \mathrm{O}_{2}$ solution.

associated to the stretching and bending of the $\mathrm{OH}$ bond at $3000-3500 \mathrm{~cm}^{-1}$ and $1419 \mathrm{~cm}^{-1}$, respectively. Also an 880 $\mathrm{cm}^{-1}$ band was observed, attributed to vibrations of the epoxy group, although small bands near the region of the $1700 \mathrm{~cm}^{-1}$ could be related to the presence of carbonyl $(\mathrm{C}=\mathrm{O})$ or carboxyl (-COO) groups formed at the edges of the graphite plate layers. These results confirm the best condition for graphene oxide plate formation. The presence of all the above oxygen in the GO layer is accompanied with loss of planarity of the affected carbons which, combined with the more hydrophilic nature of these groups, induces the penetration of solvent molecules and makes possible the separation of some layers.

According to the literature [14], the most characteristic features in the FT-IR spectrum of GO are the adsorption bands corresponding to the $\mathrm{C}=\mathrm{O}$ carbonyl stretching at $1733 \mathrm{~cm}^{-1}$, the $\mathrm{O}-\mathrm{H}$ deformation vibration at $1412 \mathrm{~cm}^{-1}$, the $\mathrm{C}-\mathrm{OH}$ stretching at $1226 \mathrm{~cm}^{-1}$, and the $\mathrm{C}-\mathrm{O}$ stretching at 


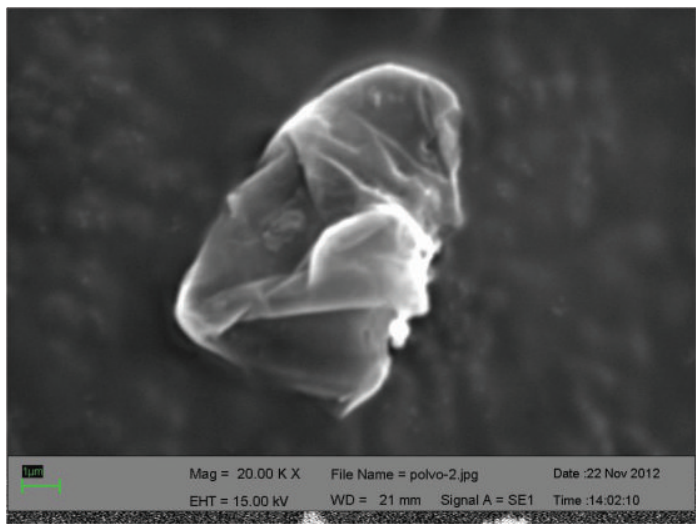

(a) GO layer

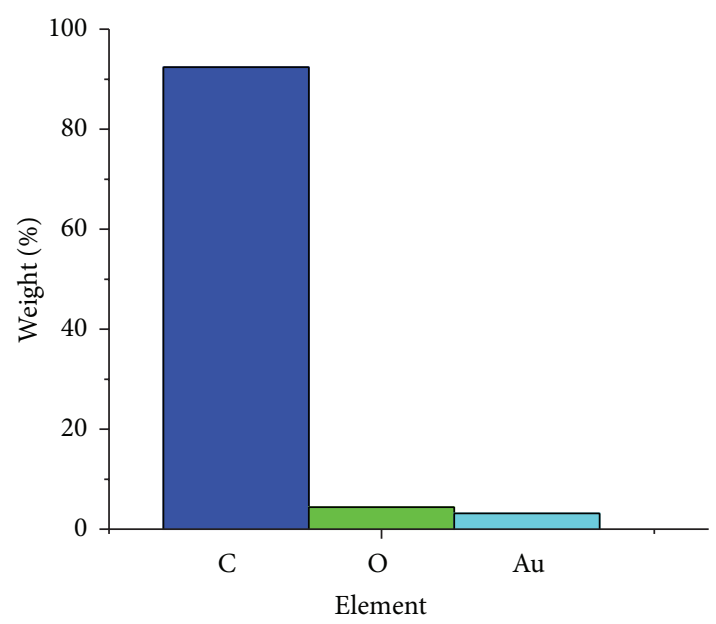

(b) EDX

FIGURE 5: SEM image of GO and the characterized area through EDX.

$1053 \mathrm{~cm}^{-1}$. The $\mathrm{O}-\mathrm{H}$ stretches appear at $3400 \mathrm{~cm}^{-1}$ as a broad and intense signal; the resonances at $1621 \mathrm{~cm}^{-1}$ are assigned to the vibrations of the adsorbed water molecules, overlapped with the $\mathrm{C}=\mathrm{C}$ skeletal vibrations of unoxidized graphitic domains. This is compared to the bands obtained (Figure 6).

Once the best GO sheets formation conditions were established, they were used to form the composite electrospun Ny/GO coating. The nylon film thickness formed during three hours was established and determined through SEM analysis and presented in Figure 7. An average around $9.5 \mu \mathrm{m}$ film thickness of nylon fibers was obtained through the electrospinning deposition. In the film area the presence of large and well-defined nylon fibers can be observed in an intricate and compact mesh that covers the substrate. Because of its size, the presence of the GO layers cannot be clearly seen.

\subsection{Electrochemical Coating Formation}

3.4.1. Polarization Curves. To obtain the best electrochemical conditions for the Ny/FGO coating formation, polarization curves were determined under acid, neutral, and basic solutions to observe the best oxidation-reduction conditions. Figure 8 presents the polarization curves, where the higher oxidation and reduction current densities can easily be observed. The best oxidation condition was obtained in $\mathrm{KOH}$ and peroxide solutions, and the best reduction with hydrogen peroxide was obtained when $\mathrm{H}_{2} \mathrm{SO}_{4}$ solution was used. These conditions were established according to the polarization curves obtained.

In view of the above-mentioned results, potentiostatic oxidation and reduction curves were applied to further oxidize carbon species and then to reduce them over the porous silica substrate containing either the electrospun Ny/GO composite film or the electrospun nylon film covered with a layer of GO, to form the Ny/FGO composite coating in both cases.

The potentiostatic oxidation/reduction polarization curves obtained, using $\mathrm{KOH}(0.5 \mathrm{M})$ or $\mathrm{H}_{2} \mathrm{SO}_{4}(\mathrm{pH}=2)$

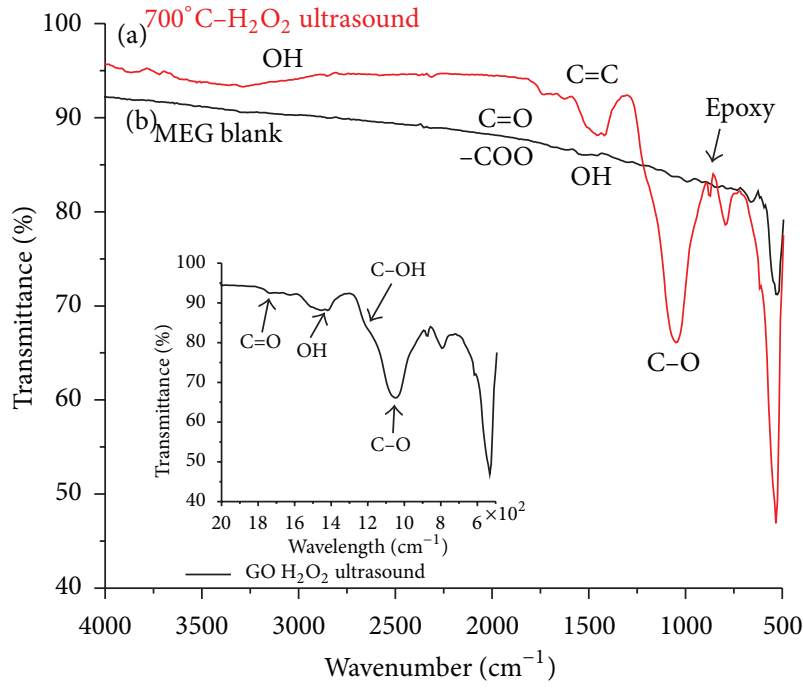

FIGURE 6: FT-IR spectra: (a) thermally pretreated graphene oxide plates in peroxide solution and ultrasonic vibration and (b) MEG blank.

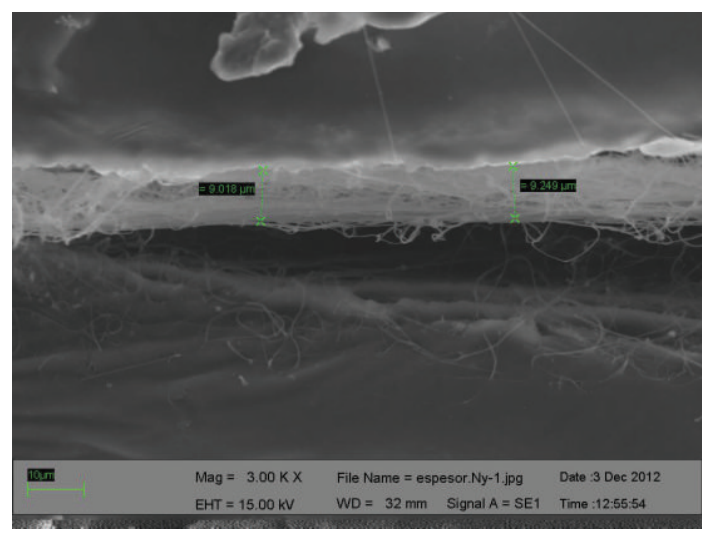

FIGURE 7: Ny/GO fibre film thickness formed after three hours of electrospinning. 


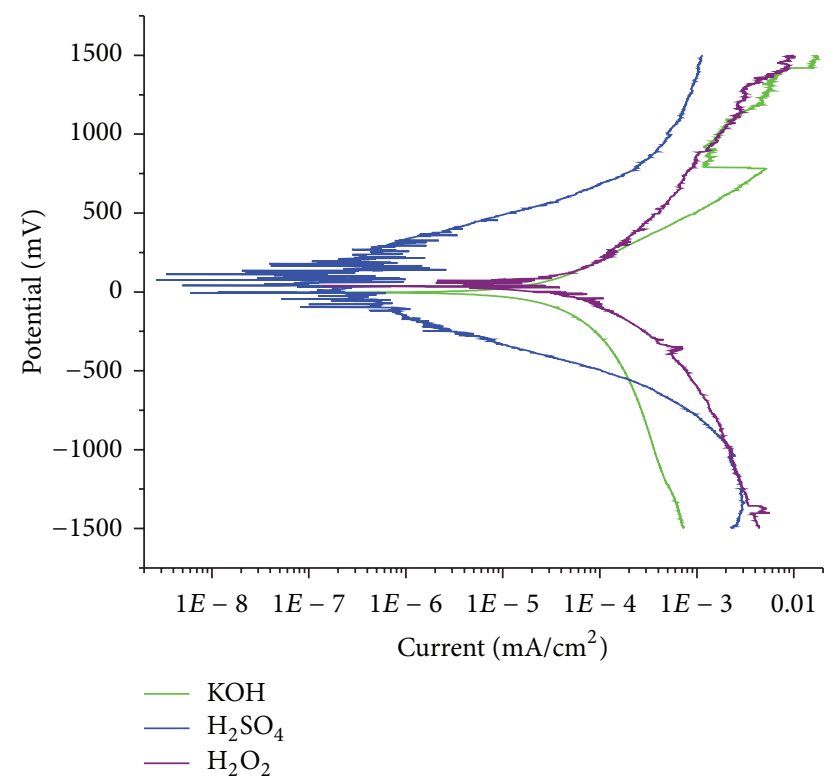

FIGURE 8: Polarization curve for electrospun Ny/FGO coating under acid, neutral, and basic solutions.

solutions, as a function of time, are presented in Figures 9(a) and 9 (b). For comparison, potentiostatic polarization curve for a porous silica electrode was performed and included as a reference sample (blank). For the potentiostatic oxidation (Figure 9(a)) and reduction (Figure 9(b)) curves, the highest current density values were for the graphene oxide deposited over the electrospun nylon film electrode. The lower values registered were for the porous silica electrode (blank), as expected. A composite electrospun Ny/FGO film coating was obtained.

Furthermore, an electrospun Ny/FGO composite coating was obtained, which SEM micrographs show a general view and magnification of the coated system (Figure 10). In Figure 10(a) a complex network of Ny/FGO plates can be observed. It is possible to observe, in the micrograph of Figure 10(b), the presence of functionalized graphite oxide layers bonded and surrounded but not crossed by the nylon fibres. This peculiar pathway suggests that the presence of hydrophilic groups in the periphery of the GO layers makes possible its interaction with the amide groups (-CO-NH-) of the nylon fibers. The nature of both species in the materials can be observed and confirmed through visible UV spectroscopy.

3.4.2. UV-Vis Characterization. In the visible UV absorption spectra of the $\mathrm{Ny} / \mathrm{GO} 0.36 \%$ and $2 \%$ systems were observed. For the Ny/FGO 2\% system an absorption peak at $230 \mathrm{~nm}$ assigned to the $\pi-\pi^{*}$ transition of the aromatic $\mathrm{C}=\mathrm{C}$ bonds is observed (Figure 11). Also, an absorption peak at $300 \mathrm{~nm}$ for both compounds is present and representing the graphite oxide reduction [15]. As long as the absorption spectrum displacement is larger towards the visible region, the graphite oxide deoxygenation is higher according to some authors [16]. This especially occurs when the reduction does not restitute the double bonds $\mathrm{C}=\mathrm{C}$ to the rest of the conjugated

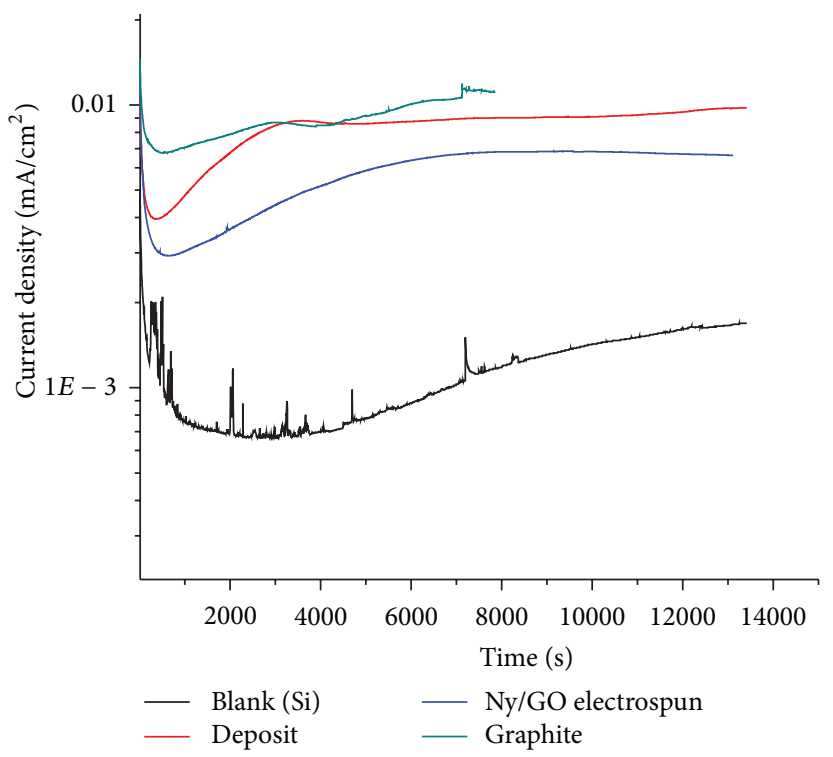

(a)

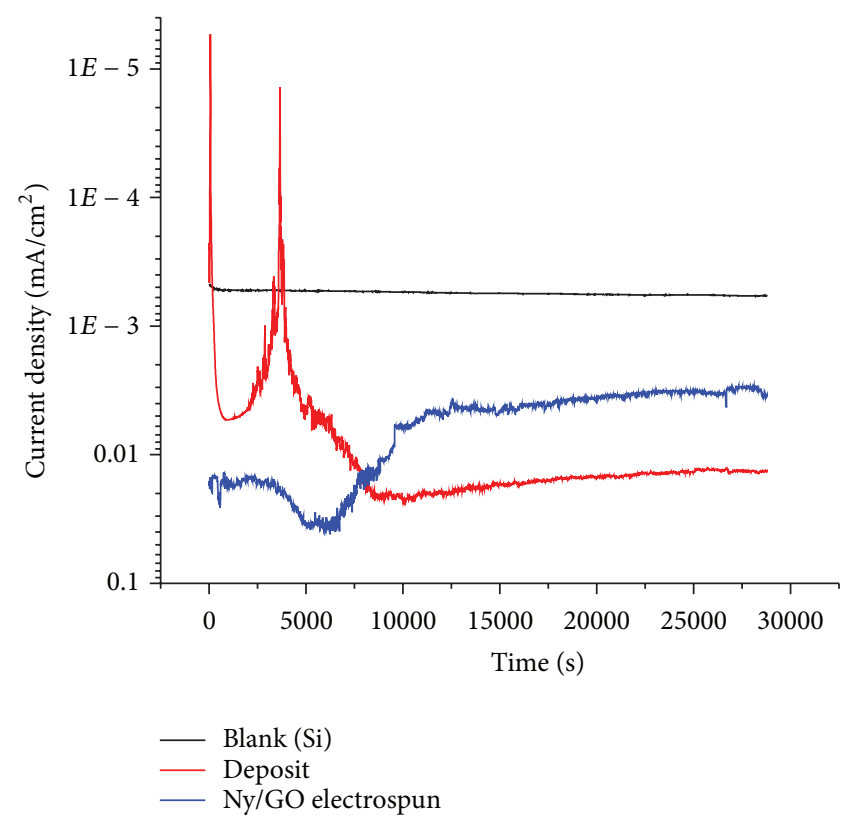

(b)

FIgUre 9: Potentiostatic curves, at $1000 \mathrm{mV}$ for the (a) oxidation of the Ny/GO in basic $\mathrm{KOH}, 0.5 \mathrm{M}$ solution during $3.5 \mathrm{hr}$ and (b) reduction of the $\mathrm{Ny} / \mathrm{GO}$ in $\mathrm{H}_{2} \mathrm{SO}_{4}, \mathrm{pH} 2$ solution during $8 \mathrm{hr}$.

$\pi$-electrons system of the graphite oxide layer. As was abovementioned, the presence of more $\mathrm{sp}^{3}$ carbon hybridization, as consequence of the oxidation reaction, increases the nonplanarity of GO. Reduction of few oxide groups was reached.

Electrochemical impedance measurements were performed to evaluate the $\mathrm{Ny} / \mathrm{FGO}$ at $2 \%$ electrospun composite coating under different $\mathrm{Na}_{2} \mathrm{SO}_{4}$ concentration solutions. The Bode plots presented in Figure 12 show the total impedance values for the Ny/FGO sample for different solution concentration. In general, an inverse relation was obtained for the overall impedance as a function of solution concentration, 
TABLE 1: Determined capacitance at low and high frequency of the Ny/FGO systems using different $\mathrm{Na}_{2} \mathrm{SO}_{4}$ concentrations.

\begin{tabular}{lccc}
\hline $\mathrm{Na}_{2} \mathrm{SO}_{4}$ concentration & $\begin{array}{c}\text { Ny/FGO 0.36\% electrospun } \\
\text { Capacitance }\left(\mathrm{F} / \mathrm{cm}^{2}\right) \\
f=0.8\end{array}$ & $\begin{array}{c}\text { Ny/FGO 2\% electrospun } \\
\text { Capacitance }\left(\mathrm{F} / \mathrm{cm}^{2}\right)\end{array}$ & $\begin{array}{c}\text { Ny/FGO 2\% deposited } \\
\text { Capacitance }\left(\mathrm{F} / \mathrm{cm}^{2}\right) \\
f=0.8\end{array}$ \\
\hline $0.001 \mathrm{M}$ & $1.37803 E-05$ & $8.90726 E-07$ & $1.52 E-4$ \\
$0.01 \mathrm{M}$ & $2.66143 E-05$ & $1.06257 E-07$ & $1.60 E-4$ \\
$0.1 \mathrm{M}$ & $4.48955 E-05$ & $8.58827 E-07$ & $1.52 E-4$ \\
$1 \mathrm{M}$ & $4.49426 E-05$ & $7.47008 E-07$ & $1.81 E-4$ \\
\hline
\end{tabular}

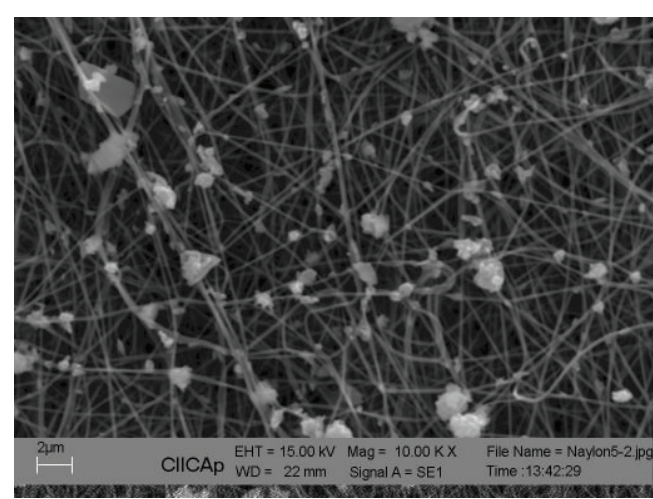

(a) general view

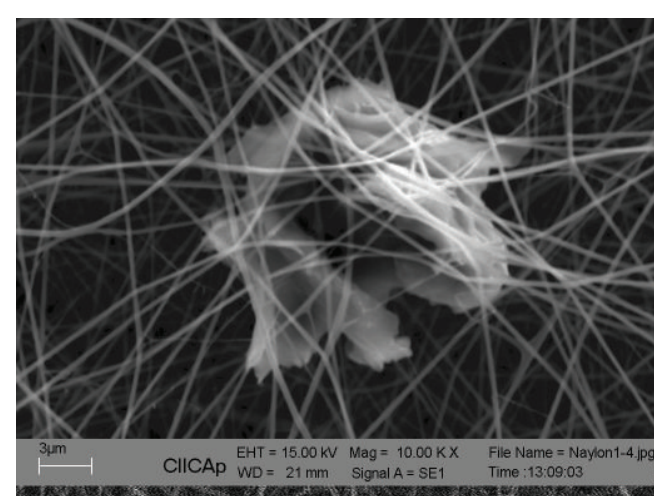

(b) detail

FIGURE 10: SEM of electrospun Ny/FGO composite at $10 \mathrm{k} x$ magnification.

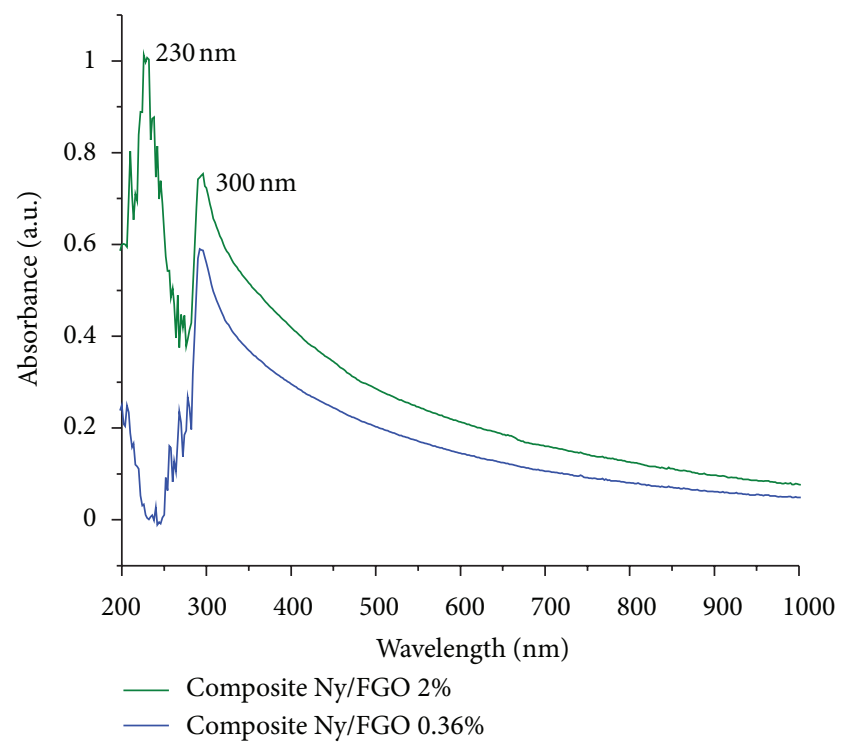

FIGURE 11: UV-Vis spectra of the systems: Ny/FGO with $2 \%$ and with $0.36 \%$.

reflecting coating performance [17]. This is possibly due to the possible difficulty of aggressive species diffusing through the coating as well as modifying the electron discharge of the cathodic reaction, therefore diminishing the metal degradation $[18,19]$. This also reflects the effects of the solution over the porous silica substrate [17].

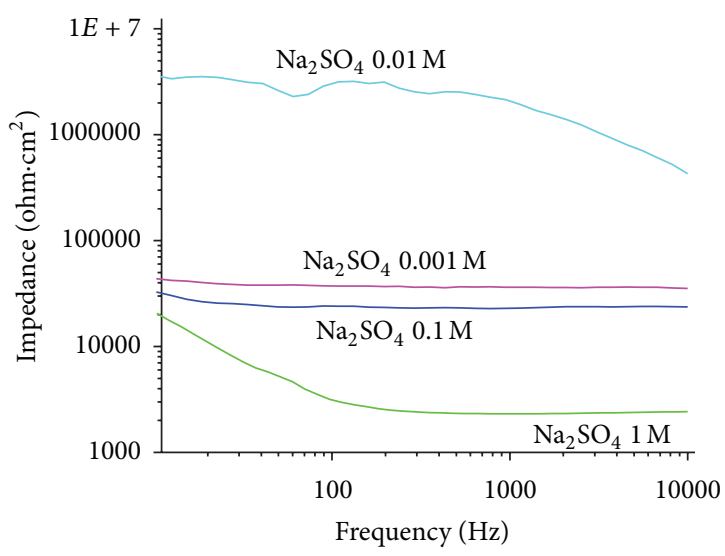

FIGURE 12: Electrochemical evaluation of the system Ny/FGO at 2\% $\mathrm{GO}$ with the impedance as a function of $\mathrm{Na}_{2} \mathrm{SO}_{4}$ solution concentration.

Coating capacitance was obtained from (1). The values obtained from the impedance parameters for $\mathrm{Ny} / \mathrm{FGO}$ at 0.36 and $2 \%$ for different $\mathrm{Na}_{2} \mathrm{SO}_{4}$ solution concentrations are shown in Table 1:

$$
C_{\text {coat }}=\frac{1}{2 \pi f R_{\text {pore }}} \text {, }
$$

where $C_{\text {coat }}$ represents the coating capacitance and $R_{\text {pore }}$ the coating resistance related to the porosity. 


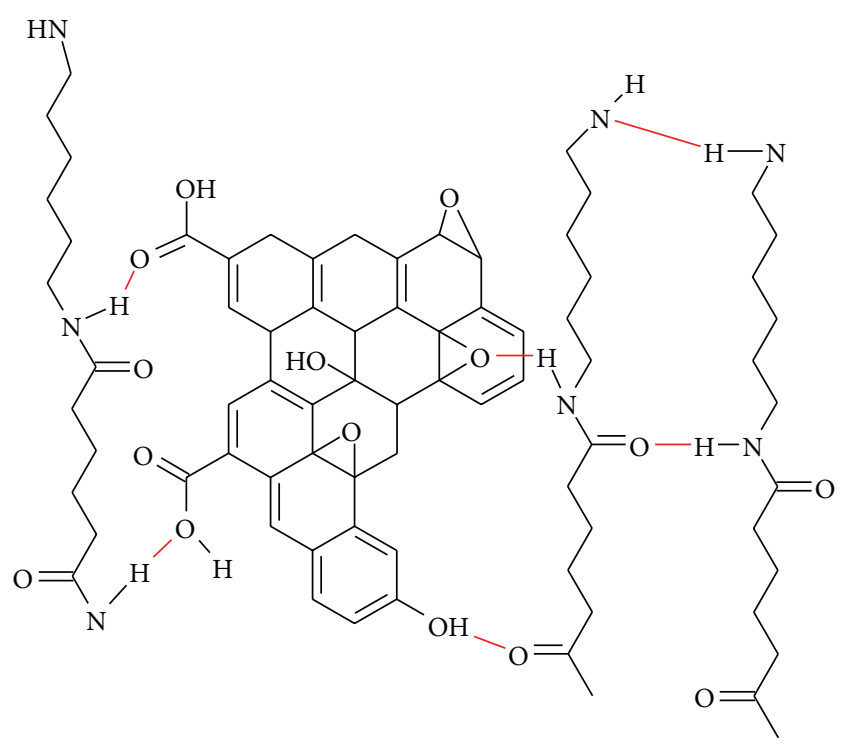

FIGURE 13: Possible coupling of nylon and FGO through hydrogen bonds and dipole-dipole interactions.

Capacitance values obtained for the Ny/FGO suggest a charge storage capacity for the coating condition. The capacitance obtained for the deposited GO sample presents higher values, therefore greater charge storage. A proposal is made of the functionalized graphene oxide, and polymeric fibres association occurs by means of the dipole-dipole and hydrogen bridge interactions, according to the proposed model in Figure 13. This union is formed between the hydrogen or oxygen from the amide group (-CO-NH-) and one hydrogen or oxygen from the functional groups present in the graphite oxide, possibly carboxyl $(-\mathrm{COOH})$ or carbonyl $(\mathrm{C}=\mathrm{O})$ groups [20].

\section{Conclusions}

A composite coating consisting of electrospun Ny/FGO was produced through electrochemical procedures. The coupling of nylon and the graphite oxide layers can be explained mainly by the interactions of the amide groups of nylon and the hydrophilic groups present in the periphery of the GO. Their coating electrochemical performance was evaluated presenting good coating properties and capacitance values. The best coating capacitance was obtained for the Ny/FGO $2 \%$ sample by deposit. Good charge storage properties were obtained.

\section{Conflict of Interests}

The authors declare in this paper there is no conflict of interests.

\section{Acknowledgments}

The authors wish to thank the Ministry of Education (SEPPROMEP) for the support provided both to the Academic Body "Desarrollo y Análisis de Materiales Avanzados" (UAEMOR-CA-43) and to the Academic Network "Diseño
Nanoscópico y Textural de Materiales Avanzados.” Finally, the authors thank CONACyT for the grants received during this work.

\section{References}

[1] D. R. Dreyer, S. Park, C. W. Bielawski, and R. S. Ruoff, "The chemistry of graphene oxide," Chemical Society Reviews, vol. 39, no. 1, pp. 228-240, 2010.

[2] C. Gómez-Navarro, R. T. Weitz, A. M. Bittner et al., "Electronic transport properties of individual chemically reduced graphene oxide sheets," Nano Letters, vol. 7, no. 11, pp. 3499-3503, 2007.

[3] A. I. Altsybeeva and S. Z. Levin, Metal Corrosion Inhibitors, edited by L. I. Antropov, Khimiya, Leningrad, Russia, 1968.

[4] R. Yukhnevich, V. Bogdanovich, E. Valashkovsky, and A. Vidukhovsky, Technika Przeciwkorozyjna, Wydawnictwa Szkolne i Pedagogiczne, Warszawa, Poland, 1976.

[5] A. L. Yarin, S. Koombhongse, and D. H. Reneker, "Taylor cone and jetting from liquid droplets in electrospinning of nanofibers," Journal of Applied Physics, vol. 90, no. 9, pp. 4836-4846, 2001.

[6] Y. M. Shin, M. M. Hohman, M. P. Brenner, and G. C. Rutledge, "Experimental characterization of electrospinning: the electrically forced jet and instabilities," Polymer, vol. 42, no. 25, pp. 9955-9967, 2001.

[7] C. Menchaca, B. Manoun, G. Martínez-Barrera, V. M. Castaño, and H. López-Valdivia, "In situ high-temperature Raman study of crystalline nylon 6,12 fibers gamma-irradiated in argon atmosphere," Journal of Physics and Chemistry of Solids, vol. 67, no. 9-10, pp. 2111-2118, 2006.

[8] C. Menchaca, I. Castañeda, A. Soto-Quintero et al., "Characterization of a "smart" hybrid varnish electrospun nylon benzotriazole copper corrosion protection coating," International Journal of Corrosion, vol. 2012, Article ID 925958, 10 pages, 2012.

[9] R. Cottis and S. Turgoose, Electrochemical Impedance and Noise, NACE Internacional, Houston, Tex, USA, 1999.

[10] J. Botana and M. Marcos, Ruido Electroquímico, Métodos de Análisis, SEPTEM, Oviedo, España, 2006.

[11] M. A. González-Núñez and J. Uruchurtu-Chavarin, "R/S fractal analysis of electrochemical noise signals of three organic coating samples under corrosion conditions," Journal of Corrosion Science and Engineering, vol. 6, supplement C117, 2003.

[12] W. S. Hummers Jr. and R. E. Offeman, "Preparation of graphitic oxide," Journal of the American Chemical Society, vol. 80, no. 6, p. 1339, 1958.

[13] K. Haubner, J. Morawski, P. Olk et al., "The route to functional graphene oxide," http://tu-dresden.de/die_tu_dresden/fakultaeten/fakultaet_mathematik_und_naturwissenschaften/fachrichtung_chemie/mc/publikationen/download/Haubner10.pdf.

[14] S. Stankovich, R. D. Piner, S. T. Nguyen, and R. S. Ruoff, "Synthesis and exfoliation of isocyanate-treated graphene oxide nanoplatelets," Carbon, vol. 44, no. 15, pp. 3342-3347, 2006.

[15] D. Li, M. B. Müller, S. Gilje, R. B. Kaner, J. Gordon, and G. Wallace, "Processable aqueous dispersions of graphene nanosheets," Nature Nanotechnology, vol. 3, no. 2, pp. 101-105, 2008.

[16] J. I. Paredes, S. Villar-Rodil, M. J. Fernández-Merino, L. Guardia, A. Martínez-Alonso, and J. M. D. Tascón, "Environmentally friendly approaches toward the mass production of processable graphene from graphite oxide," Journal of Materials Chemistry, vol. 21, pp. 298-306, 2011. 
[17] J. Uruchurtu and J. L. Ramírez, Método Experimental en la Corrosión: Impedancia Electroquímica, Editorial Academica Española, Berlin, Germany, 2011.

[18] A. S. Khanna, M. K. Totlani, and S. K. Singh, Corrosion and Its Control, vol. 2, Elsevier, Amsterdam, The Netherlands, 1998.

[19] D. H. Reneker and I. Chun, "Nanometre diameter fibres of polymer, produced by electrospinning," Nanotechnology, vol. 7, no. 3, pp. 216-223, 1996.

[20] A. Castro-Beltrán, S. Sepúlveda-Guzmán, W. J. de la CruzHernández, and R. Cruz-Silva, "Obtención de grafeno mediante la reducción química del óxido de grafito," Ingenierías, vol. 7-9, no. 14, article 52, 2011. 

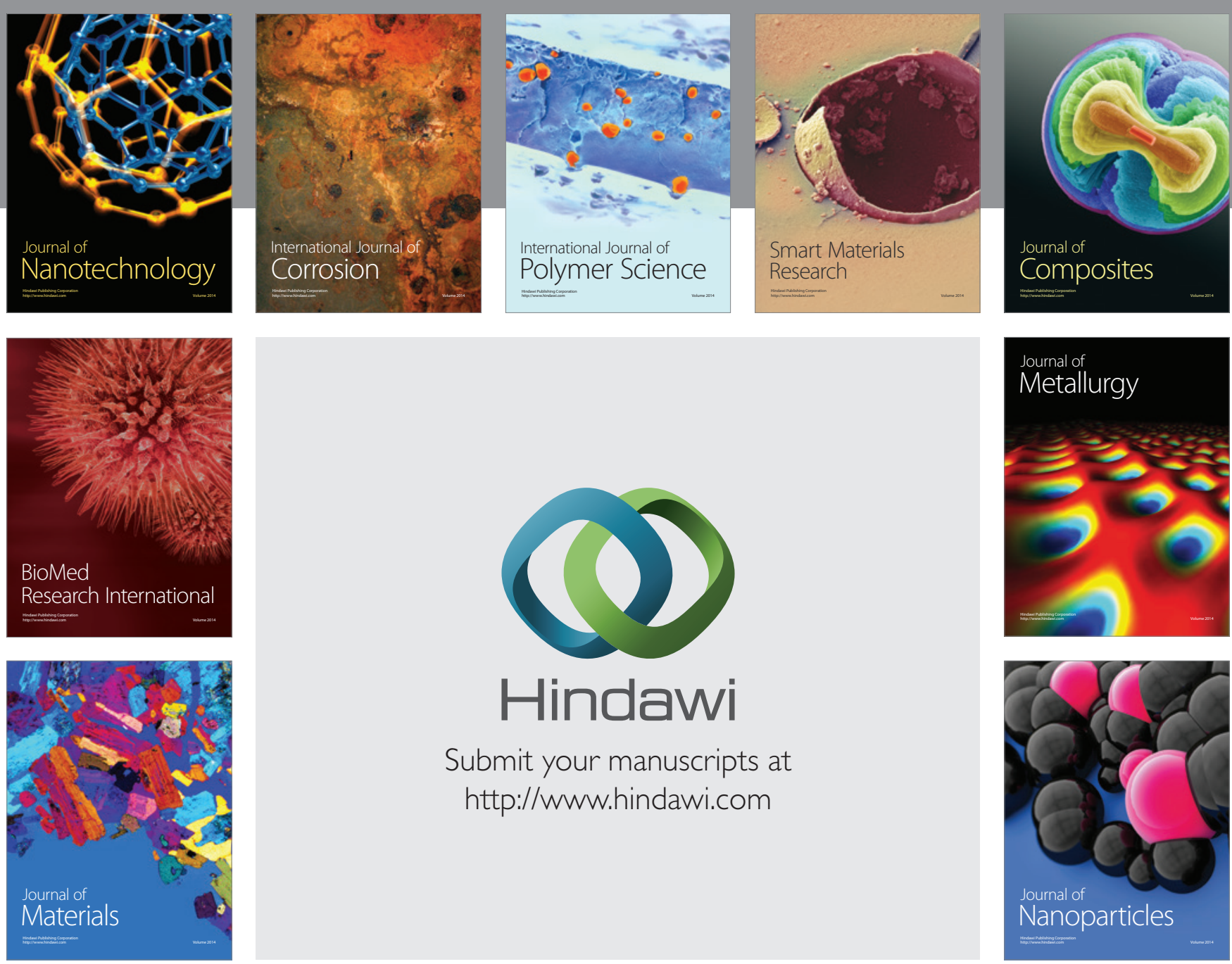

Submit your manuscripts at http://www.hindawi.com
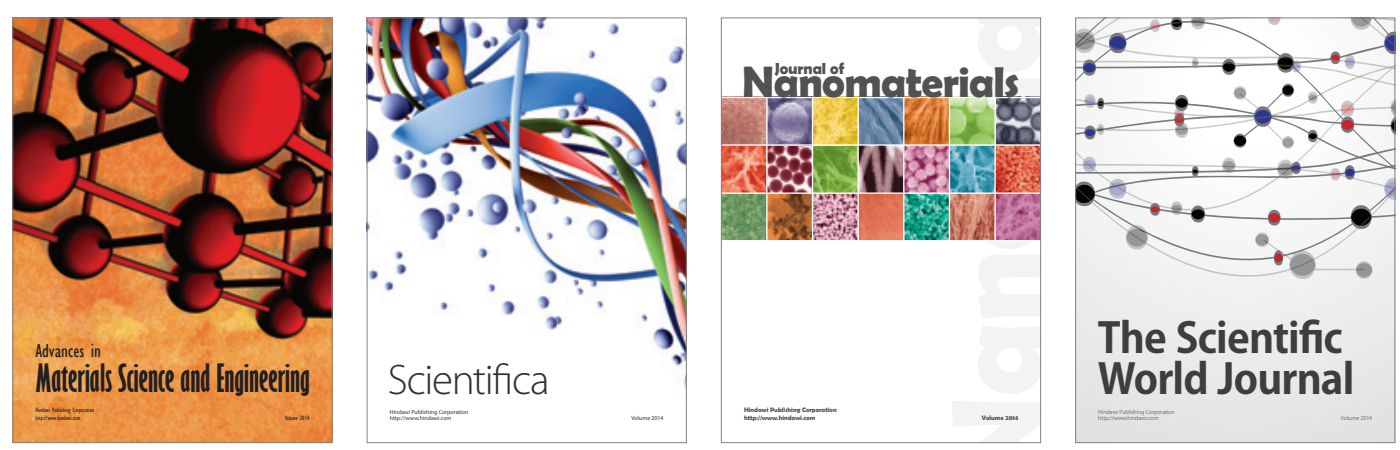

\section{The Scientific World Journal}
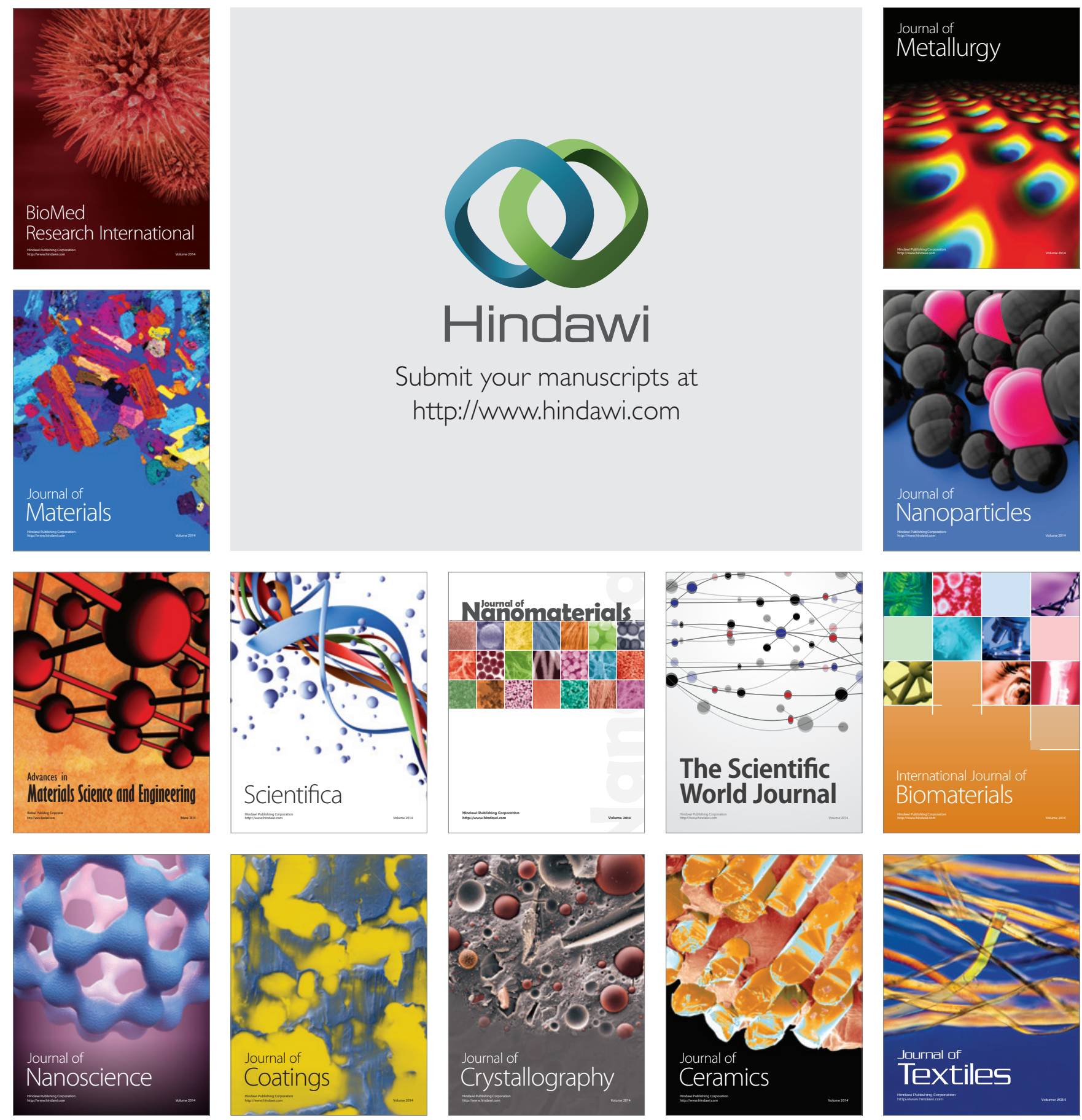